\title{
Extending the Phenotypic Spectrum of Huntington Disease: Hypothermia
}

\author{
Şule Altıner ${ }^{\mathrm{a}}$ Senol Ardic ${ }^{\mathrm{b}}$ Alper H. Çebi ${ }^{\mathrm{c}}$ \\ ${ }^{a}$ Department of Medical Genetics, Trabzon Kanuni Training and Research Hospital, University of Health Sciences, \\ Trabzon, Turkey; ${ }^{b}$ Department of Emergency Medicine, Faculty of Medicine, University of Health Sciences, Trabzon, \\ Turkey; ${ }^{\circ}$ Department of Medical Genetics, Karadeniz Technical University School of Medicine, Trabzon, Turkey
}

\section{Established Facts}

- Huntington disease (HD) is typically characterized by movement disorder, psychiatric symptoms, and cognitive decline. Sleep problems, weight loss, and cachexia are also common findings. Glucose intolerance, osteoporosis, cardiac failure, gastrointestinal abnormalities, and testicular atrophy are other non-neuronal manifestations of HD.

- Association of hypothermia with HD is only reported in animal models.

\section{Novel Insights}

- This is the first report describing hypothermia in humans with HD.

\section{Keywords}

Huntingtin $\cdot$ Huntington disease $\cdot$ Hypothermia $\cdot$ PGC-1a . Thermoregulation

\begin{abstract}
Huntington disease (HD) is an autosomal dominant progressive neurodegenerative disorder associated with expanded CAG repeat size in the huntingtin gene and usually presenting with movement disorder, psychiatric symptoms, and cognitive decline. Sleep problems, weight loss, and cachexia are also common. Here, we report a patient presenting with hypothermia in late-stage HD. Although thermoregulatory defects were documented in animal models, this is the first report describing HD with hypothermia in humans.

(c) 2020 S. Karger AG, Basel
\end{abstract}

\section{KARGER}

(๑) 2020 S. Karger AG, Basel
Huntington disease (HD) was described in 1872 by George Huntington [Huntington, 1872]. It is inherited in an autosomal dominant pattern. The worldwide prevalence is 2.7/100,000 [Pringsheim et al., 2012]. Three characteristic features are motor dysfunction, cognitive impairment, and neuropsychiatric features. The symptoms of HD typically start in adulthood. Putamen and striatum atrophy are the neuropathological signs of the disease [Bates et al., 2015].

The genetic basis of HD is the expanded CAG repeat size in exon 1 of the huntingtin (HTT) gene, which is located in chromosome 4p16 [MacDonald et al., 1993]. In normal population, CAG repeat size ranges from 6 to 35 . The 36-39 CAG repeats might result in a milder phenotype with incomplete penetrance. When CAG repeat length reaches 40 , the mutation is highly penetrant, and the symptoms of disease manifest in the patients [Bates et

Sule Altıner, MD

Department of Medical Genetics, Trabzon Kanuni Training and Research Hospital, University of Health Sciences

Trabzon 61290 (Turkey)

E-Mail altinersule@gmail.com 
al., 2015]. CAG repeat code for polyglutamine (polyQ) and mutant huntingtin contains longer polyQ. Abnormal aggregate caused by mutant huntingtin protein is considered to be the result of toxic gain of function of HTT. On the other hand, mutant protein affects several proteins and a dominant negative effect of mutant protein could also contribute to disease pathogenesis [Walker, 2007].

Diagnosis of HD is based on clinical evaluation, family history, and genetic testing. Neuroimaging can also support the diagnosis [Bates et al., 2015]. Here, we present a patient with hypothermia as an uncommon finding, accompanying late-stage $\mathrm{HD}$. Hypothermia has been reported only in animal models. To our knowledge, this is the first report describing HD with hypothermia in humans.

\section{Case Report}

The patient was a 29-year-old male admitted to the emergency department by his caregiver due to deterioration of health conditions. He was bedridden, in a nursing home, and needed assistance for all activities of daily living. According to first evaluation, the patient was cachectic, had both spasticity and rigidity. Glasgow scale was 12 . He had deterioration in vital signs. His temperature was $34^{\circ} \mathrm{C}$ (axillary), blood pressure $70 / 50 \mathrm{mmHg}$, pulse $45 / \mathrm{min}$, respiratory rate $18 / \mathrm{min}$, and oxygen saturation $94 \%$. Infrared heater and heater blankets were used to adjust the body temperature. After initial treatment, he was admitted to the intensive care unit. Hypoglycemia was detected $(50 \mathrm{mg} / \mathrm{dL})$. Enteral nutrition was delivered by a nasogastric tube, and vital signs were improved by atropine and dopamine.

At the time of admission, he could not talk and not give any medical history. According to anamnesis (caregiver), the patient had a family history of a similar disorder. The patient was lonely, had no known living relatives. A medical geneticist at the intensive care unit was contacted, and molecular genetic testing for prediagnosis of HD was planned. Despite all the efforts, the patient died on the 8th day of hospitalization.

\section{Methods and Results}

DNA isolated from the patient's peripheral blood sample was used for the analysis of CAG repeat size in the HTT gene. Huntington's Disease GScan ${ }^{\mathrm{TM}}$ Ver2 Kits (Gene Link) was used according to the manufacturer's instructions. Applied Biosystem 3130XL Genetic Analyzer was used. The formula for determining PCR fragment size is $186+3 n$ ( $n$ indicating the number of CAG repeats. Genetic testing for HD confirmed the diagnosis, which revealed 22 CAG repeats in one allele and 52 repeats in the other allele.

\section{Discussion}

HD is typically characterized by movement disorder, psychiatric symptoms, and cognitive decline. Movement disorder can be divided into 2 groups: involuntary move- ment disorder as chorea and impairment of voluntary movements such as dystonia, together with an unsteady gait, dysarthria, dysphagia, and oculomotor disorders. Cognitive functions prominently affect attention, memory, and planning. Psychiatric symptoms include depression, apathy, irritability, and schizophrenia-like depression [Bates et al., 2015]. All these symptoms are relevant with neurodegeneration of basal ganglia and cerebral cortex; typical symptoms such as sleep problems, weight loss, and cachexia are also common. Glucose intolerance, osteoporosis, cardiac failure, gastrointestinal abnormalities, and testicular atrophy are other non-neuronal manifestations of HD. These symptoms are not straightly associated with neurodegeneration, but are considered to be secondary to general sickness or a result of neurological dysfunction. Moreover, mutant huntingtin is expressed in peripheral tissues, and peripheral abnormalities in HD could be due to a local effect of mutant huntingtin [van der Burg et al., 2009].

The patient had hypoglycemia in addition to other findings. Although glucose metabolism alterations are shown in HD mice models, it is still controversial in human HD. Larger studies are needed in human HD with comprehensive follow-up data [Montojo et al., 2017]. Hypoglycemia in our patient probably is a component or a result of deterioration of general conditions.

Hypothermia is an uncommon finding in HD. Association of hypothermia with HD is only reported in animal models, and it was first recognized in 2006 while screening metabolic parameters of HD mice models [Weydt et al., 2018]. All HD mice were shown to develop hypothermia, and the body temperature of some of them dropped to below $27^{\circ} \mathrm{C}$ with progression of motor symptoms and weight loss. Cold challenge was also tested at $4^{\circ} \mathrm{C}$, and $\mathrm{HD}$ transgenic mice were not able to maintain normal thermoregulation [Weydt et al., 2006]. Besides, a disruption of diurnal temperature cycles in HD mice models was reported by Fisher et al. [2013].

Brown adipose tissue (BAT), skeletal muscle, and hypothalamus are components involved in thermoregulation [Tansey and Johnson, 2015], and disorders in the abovementioned contribute to hypothermia. Mitochondrial uncoupling protein 1 (UCPI) mediates heat production in BAT by uncoupling the electron transport chain from ATP synthesis [Fedorenko et al., 2012]. It was shown in HD mice models that BAT was remarkably vacuoloized, and UCP1 response to cold stimuli was blunted [Weydt et al., 2006]. An in vivo muscle study showed an impaired energy metabolism by comparing the adenosine triphosphate content with controls, which was lower in HD patients [Lodi et al., 2000]. 
Besides, PGC-1 $\alpha$, belonging to the PGC-1 related coactivator family, regulates metabolic processes such as mitochondrial biogenesis and muscle fiber type switching [Lin et al., 2004]. PGC-1 1 is highly expressed in BAT, and its expression is elevated in mice BAT and skeletal muscle after exposure to cold. It mediates expression of UCP1 and plays a role in adaptive thermogenesis [Puigserver et al., 1998]. The role of PGC-1a in HD in mouse models was investigated. Weydt et al. [2006] showed that PGC-1a-dependent genes along with UCPI were diminished. Chaturvedi et al. [2009] showed an impaired function of PGC-1a in muscle biopsies from human HD and muscle of mouse models with HD. These suggested that impaired PGC-1a function may contribute to thermoregulation in HD.

Hypothalamus, known to regulate thermogenesis [Nagashima et al., 2000], is also affected by HD [Politis et al., 2008]. Soylu-Kucharz et al. [2015] showed downregulation of UCP1 and PGC-1 $\alpha$ in BAT in mice models with targeted expression of mutant huntingtin only in the hypothalamus. Therefore, hypothalamic dysfunction may contribute to hypothermia in HD.

Hypothermia is probably a sign of very advanced stages of the disease when usually the diagnosis already has been established. Furthermore, patients with very advanced stages of other diseases may also have hypothermia in the terminal phase, but this is usually neither recorded nor reported. Little is found in the literature. But recently, Nakayama et al. [2018] showed that hypothermia was significantly associated with progressive amyotrophic lateral sclerosis.

In this study, we present a case with hypothermia in late-stage HD. Disorders of the hypothalamus, BAT, and skeletal muscle may contribute to the phenotype. Regarding that these systems are also affected in human HD, hypothermia may be underestimated. This case also is a good example of showing a multidisciplinary approach in the era of personalized medicine.

\section{Statement of Ethics}

The authors have no ethical conflicts to disclose.

\section{Disclosure Statement}

The authors have no conflicts of interest to declare.

\section{Author Contributions}

Ş. Altıner obtained the patient information, designed the work, and wrote the manuscript. S. Ardic obtained the patient information and contributed to the manuscript. A.H. Cebi analyzed the data and contributed to the manuscript. All authors read and confirmed the final manuscript.

\section{References}

Bates GP, Dorsey R, Gusella JF, Hayden MR, Kay C, et al: Huntington disease. Nat Rev Dis Primers 1:15005 (2015).

- Chaturvedi RK, Adhihetty P, Shukla S, Hennessy $\mathrm{T}$, Calingasan $\mathrm{N}$, et al: Impaired PGC-1a function in muscle in Huntington's disease. Hum Mol Genet 18:3048-3065 (2009).

-Fedorenko A, Lishko PV, Kirichok Y: Mechanism of fatty-acid-dependent UCP1 uncoupling in brown fat mitochondria. Cell 151:400-413 (2012).

- Fisher SP, Black SW, Schwartz MD, Wilk AJ, Chen TM, et al: Longitudinal analysis of the electroencephalogram and sleep phenotype in the R6/2 mouse model of Huntington's disease. Brain 136:2159-2172 (2013).

Huntington G: On chorea. (1872).

Lin J, Wu PH, Tarr PT, Lindenberg KS, St-Pierre $\mathrm{J}$, et al: Defects in adaptive energy metabolism with CNS-linked hyperactivity in PGC-1a null mice. Cell 119:121-135 (2004).

Lodi R, Schapira AH, Manners D, Styles P, Wood $\mathrm{NW}$, et al: Abnormal in vivo skeletal muscle energy metabolism in Huntington's disease and dentatorubropallidoluysian atrophy. Ann Neurol 48:72-76 (2000).
MacDonald ME, Ambrose CM, Duyao MP, Myers RH, Lin C, et al: A novel gene containing a trinucleotide repeat that is expanded and unstable on Huntington's disease chromosomes. Cell 72:971-983 (1993).

Montojo MT, Aganzo M, González N: Huntington's disease and diabetes: chronological sequence of its association. J Huntingtons Dis 6: 179-188 (2017).

- Nagashima K, Nakai S, Tanaka M, Kanosue K: Neuronal circuitries involved in thermoregulation. Auton Neurosci 85:18-25 (2000).

Nakayama Y, Shimizu T, Matsuda C, Haraguchi M, Hayashi K, et al: Non-motor manifestations in ALS patients with tracheostomy and invasive ventilation. Muscle Nerve 57:735741 (2018).

Politis M, Pavese N, Tai YF, Tabrizi SJ, Barker RA, Piccini P: Hypothalamic involvement in Huntington's disease: an in vivo PET study. Brain 131:2860-2869 (2008).

Pringsheim T, Wiltshire K, Day L, Dykeman J, Steeves T, Jette N: The incidence and prevalence of Huntington's disease: a systematic review and meta-analysis. Mov Disord 27: 1083-1091 (2012).
Puigserver P, Wu Z, Park CW, Graves R, Wright M, Spiegelman BM: A cold-inducible coactivator of nuclear receptors linked to adaptive thermogenesis. Cell 92:829-839 (1998).

-Soylu-Kucharz R, Adlesic N, Baldo B, Kirik D, Petersén A: Hypothalamic overexpression of mutant huntingtin causes dysregulation of brown adipose tissue. Sci Rep 5:14598 (2015).

Tansey EA, Johnson CD: Recent advances in thermoregulation. Adv Physiol Educ 39:139-148 (2015).

van der Burg JM, Björkqvist M, Brundin P: Beyond the brain: widespread pathology in Huntington's disease. Lancet Neurol 8:765774 (2009).

-Walker FO: Huntington's disease. Lancet 369: 218-228 (2007).

Weydt P, Pineda VV, Torrence AE, Libby RT, Satterfield TF, et al: Thermoregulatory and metabolic defects in Huntington's disease transgenic mice implicate PGC-1 $\alpha$ in Huntington's disease neurodegeneration. Cell Metab 4: 349-362 (2006).

-Weydt P, Dupuis L, Petersen Å: Thermoregulatory disorders in Huntington disease. Handb Clin Neurol 157:761-775 (2018). 